\title{
Decay of Impurity Nano-inclusions of Cobalt in Silicon under the Influence of Thermal Annealing
}

Nozim Turgunov*

Academy of the Ministry of Internal Affairs of the Republic of Uzbekistan, Tashkent, Uzbekistan

\begin{abstract}
The influence of a thermoannealing on electrical conduction of silicon monocrystals doped by cobalt has been studied. Also, analysis of sequence of the impurity nanoinclusion's disinteration under influence of thermoannealing has been carried out by the method of electron-probe microanalysis.
\end{abstract}

Keywords: Impurity nano-inclusions; Electron probe microanalysis; Thermal annealing; Decay of impurity nano-inclusions

\section{Introduction}

As is known, impurity clusters significantly affect the electrophysical properties of silicon single crystals. Particular attention is drawn to the behavior of impurity nanotriations under the influence of external influences. The state and behavior of impurity atoms of transition metals under the influence of thermal annealing (TA) is of great interest from the point of view of controlling the electrophysical properties of silicon single crystals. In this connection, the effect of TA on the electrical conductivity of silicon doped with cobalt, as well as the kinetics of the decay of impurity nano-inclusions of cobalt under the influence of TO, were investigated in this paper [1].

\section{Materials and Methods}

The studies were carried out with $\mathrm{n}-\mathrm{Si}<\mathrm{Co}>$ samples, which were obtained on the basis of the initial single-crystal silicon of the electronic conductivity of the KEF brand, with a specific resistance $\rho=20 \Omega \cdot \mathrm{cm}$. The diffusion temperature of cobalt in silicon was $1523 \mathrm{~K}$. The temperature in the furnace was measured with the help of a thermo-electronically active power of a platinum-platinum-rhodium thermocouple. The cooling rate of samples of $\mathrm{n}-\mathrm{Si}<\mathrm{Co}>$ after diffusion with cooling rate $10 \mathrm{~K} / \mathrm{s}$. All samples were $8 \times 4 \times 2 \mathrm{~mm}$ in the form of a parallelepiped. Samples were subjected to isothermal treatment at temperatures of $373-1273 \mathrm{~K}$ in a time interval of 5-60 minutes followed by sharp quenching. After each annealing step, the electrical properties of the samples were investigated. In order to clarify the nature of the effect of heat treatment, control specimens without a dopant were studied and subjected to annealing under the same conditions. Structural analysis of the impurity nano-inclusions was carried out using the Superprobe JXA-8800R electron probe microanalyzer [2].

The results of investigations of the dependence of the value of $\rho$ on the annealing time in samples of $\mathrm{n}-\mathrm{Si}<\mathrm{Co}>$ with specific resistivity $\rho=9 \times 10^{3} \Omega \cdot \mathrm{cm}$ showed that at TA in the temperature range $373-573 \mathrm{~K}$ no significant changes occur (curve 1 in Figure 1). At subsequent TA, at $623-1073 \mathrm{~K}$ for 5-20 minutes, an increase in the value of $\rho$ (curves $2-4$ in Figure 1) is observed in samples of $\mathrm{n}-\mathrm{Si}\langle\mathrm{Co}\rangle$. With increasing annealing time, the curves pass through a maximum, and then the value of $\rho$ of the samples decreases. Dependences of $\rho$ on the annealing time in $\mathrm{n}$ - $\mathrm{Si}<\mathrm{Co}>$ samples show a tendency according to which the maximum happens earlier with an increase in the TA temperature, and the rate of decrease of the curves increases [3].

This character of the dependence of samples on the TA time can be explained by the consequence of two processes. At the initial stages of thermal annealing at $\mathrm{T} \geq 673 \mathrm{~K}$, the impurity atoms located at the lattice sites become interstices, leaving vacancies. With increasing temperature and time of TA, such a transition of impurity atoms increases. Consequently, the resistivity of the samples increases. In the second stage, impurity microinclusions disintegrate, as a result the released impurity atoms pass into the free lattice sites, so if in the electroactive state [4].

For subsequent $\mathrm{TA}$, at $\mathrm{T}=1173 \mathrm{~K}$, a sharp decrease in the value of $\mathrm{n}$ samples of $\mathrm{n}-\mathrm{Si}<\mathrm{Co}>$ is observed for 10 minutes, the value of the resistivity of the samples approaches the initial value (curve 5 in Figure 1).

\section{Discussion}

To elucidate the nature of this change in the electrical conductivity

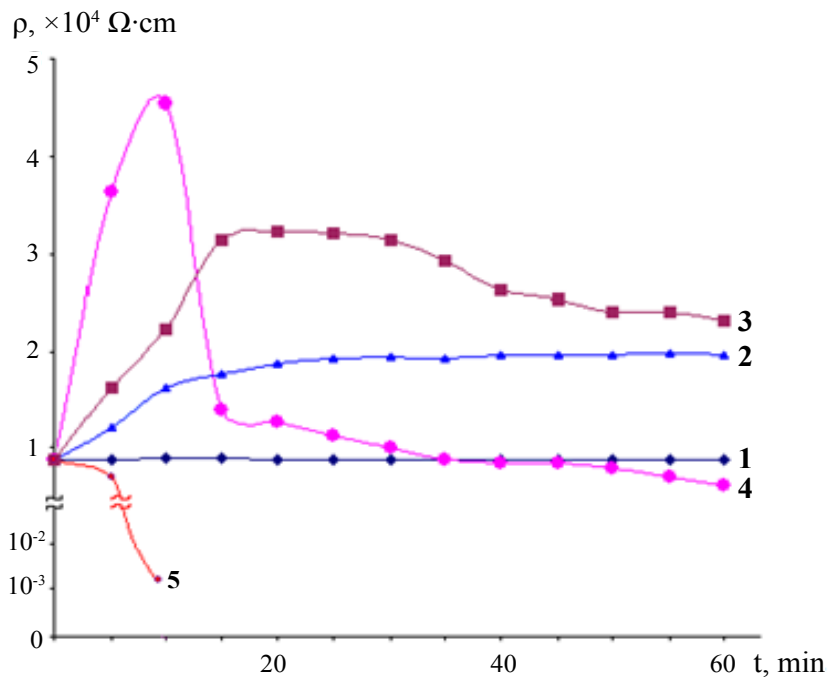

Figure 1: Dependence of the value of $\rho$ on the annealing time in samples of $\mathrm{n}-\mathrm{Si}<\mathrm{Co}>$ at TA: (1) $473 \mathrm{~K}$; (2) $623 \mathrm{~K}$; (3) $873 \mathrm{~K}$; (4) $1073 \mathrm{~K}$; (5) $1173 \mathrm{~K}$.

${ }^{*}$ Corresponding author: Nozim Turgunov, Associate professor, Academy of the Ministry of Internal Affairs of the Republic of Uzbekistan, Tashkent, Uzbekistan, Tel: +998 7126522 52; E-mail: tna_1975@mail.ru

Received May 16, 2018; Accepted May 30, 2018; Published June 10, 2018

Citation: Turgunov N (2018) Decay of Impurity Nano-inclusions of Cobalt in Silicon under the Influence of Thermal Annealing. J Material Sci Eng 7: 458. doi: 10.4172/2169-0022.1000458

Copyright: (c) 2018 Turgunov N. This is an open-access article distributed under the terms of the Creative Commons Attribution License, which permits unrestricted use, distribution, and reproduction in any medium, provided the original author and source are credited. 
Citation: Turgunov N (2018) Decay of Impurity Nano-inclusions of Cobalt in Silicon under the Influence of Thermal Annealing. J Material Sci Eng 7: 458. doi: 10.4172/2169-0022.1000458

Page 2 of 2

of the samples under the influence of TA, complex microstructural analyzes of impurity nano-inclusions in $\mathrm{n}-\mathrm{Si}<\mathrm{Co}>$ samples were carried out using an electron probe microanalyzer before and after the TA [5].

The results of microstructural studies of $\mathrm{Si}<\mathrm{Co}>$ samples under the influence of $\mathrm{TA}$ at temperatures $\mathrm{T}<673 \mathrm{~K}$ for $30-40$ minutes show a decrease in the density of impurity nano-inclusions of cobalt. It was found out that in the process of thermal annealing a partial decomposition of nano-inclusions takes place with sizes up to $\sim 500$ $\mathrm{nm}$, having needle-shaped, disk-like, plate-shaped forms.

Under the influence of TA, at $\mathrm{T}=1173 \mathrm{~K}$, decay of larger impurity microinclusions $(\sim 800 \mathrm{~nm})$ with spherical forms is observed. Figure 2 shows micrographs of a sample of $\mathrm{n}-\mathrm{Si}<\mathrm{Co}>$ before and after TA. As can be seen, small nano-inclusions in samples of $\mathrm{Si}<\mathrm{Co}>$ after TA practically disappear; under the influence of thermal annealing, their complete decay occurs.
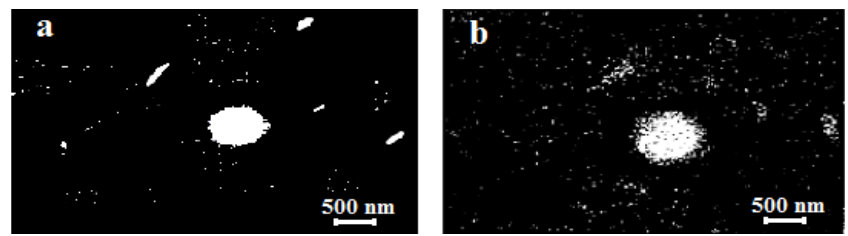

Figure 2: Impurity nanoinclusions of cobalt in silicon before (a) and after (b) $\mathrm{TA}$ at $\mathrm{T}=1173 \mathrm{~K}$.

\section{Conclusion}

Thus, on the basis of the obtained experimental results, two stages can be distinguished in the kinetics of the change in the electrical properties of silicon with impurity nano-inclusions. At the first stage of the TA, the impurity atoms located at the lattice sites are transferred to the interstices, leaving vacancies. In the second stage, impurity nanoinclusions disintegrate, as a result of which the released impurity atoms pass into the free lattice sites, i.e. in the electroactive state, which leads to a sharp decrease in the value of the resistivity.

\section{References}

1. Talanin VI, Talanin IE (2013) Application of the diffusion model for the formation of growth microdefects for the description of defect formation in heat-treated single crystals of silicon. Physics of the Solid State 55: 247-251.

2. Feklisova OV, Yakimov EB (2011) Electrical properties of plastically deformed silicon upon interaction with iron impurity. FTT 53: 1175-1178.

3. Kissinger G, Kot D, Klingsporn M, Schubert MA, Sattler A, et al. (2015) Investigation of the Copper Gettering Mechanism of Oxide Precipitates in Silicon. J Solid State Sci Technol 4: 124-129.

4. Zainabidinov SZ, Turgunov NA (2004) Formation and kinetics of decomposition of impurity nickel precipitates in silicon. Russian Physics Journal 47: 13071309.

5. Zainabidinov SZ, Musaev KN, Turgunov NA, Turaev AR (2012) Dopant microassociation mechanisms in $\mathrm{Si}<\mathrm{Mn}>$ and $\mathrm{Si}<\mathrm{Ni}>$. Inorganic Materials 48: 1065-1069. 